\title{
A produção escrita de alunos com e sem síndrome de Down: uma análise da coerência textual ${ }^{1}$
}

\section{The written production of students with and without Down syndrome: an analysis of textual coherence}

\author{
Adriana Leite Limaverde Gomes ${ }^{2}$
}

\begin{abstract}
RESUMO
Neste trabalho, analisa-se a coerência textual a partir da reescrita do conto de Rapunzel. Baseia-se em uma abordagem psicogenética da língua escrita. Participaram desse estudo nove alunos, sendo seis com síndrome de Down (Grupo I) e os outros três sem deficiência (Grupo II). Eles cursavam entre o $2^{\circ}$ e $8^{\circ}$ anos do Ensino Fundamental em escolas regulares. O procedimento de produção textual consistiu em um encontro individual, cuja solicitação de produção escrita era precedida pela leitura do conto pela pesquisadora. Os dados indicaram a presença da coerência textual nos dois grupos, embora mais frequente nas produções do grupo II, que demonstrava maior competência com os elementos de coerência textual. O grupo II apresentou estratégias poderosas para mobilizar os recursos cognitivos que permitiram articular conhecimentos anteriores e focalizá-los na produção e articulação de suas ideias no texto. O grupo I, na sua maioria, experimentava dificuldades em elaborar um desfecho em estreita relação com as partes que compunham o texto. Não apresentaram, porém, dificuldades em definir e manter a personagem principal ao longo de toda a história escrita, mesmo quando a história era incoerente se considerarmos outros indicadores. Qualitativamente, os textos dos alunos com síndrome de Down se diferenciaram daqueles produzidos pelo grupo II. Não identificamos, porém, características que podem representar especificidades na produção escrita dos alunos com
\end{abstract} (CAPES).

${ }^{1}$ Pesquisa financiada pela Coordenação de Aperfeiçoamento de Pessoal de Nível Superior

${ }^{2}$ Doutora em Educação pela Universidade Federal do Ceará. Professora Faculdade de Educação da UFC; Brasil. E-mail: adrianalimaverde@ufc.br 
essa síndrome, visto que alguns alunos com síndrome de Down produziram textos apresentando coerência.

Palavras-chave: produção textual; síndrome de Down; coerência textual.

\begin{abstract}
This work examines the textual coherence from the rewriting of the tale of Rapunzel. It is based on a psychogenetic approach of written language. Nine students participated in this study, six with Down syndrome (Group I) and the other three without disabilities (Group II). They were enrolled between 2nd and 8th years of Primary Education in regular schools. The procedure of textual production consisted in an individual meeting, whose request for written production was preceded by the reading of the story by the researcher. The data indicated the presence of textual coherence in the two groups, although more frequent in productions of group II, which showed greater competence with the elements of textual coherence. Group II presented powerful strategies to mobilize the cognitive resources that enabled to articulate previous knowledge and to focus them in the production and articulation of their ideas in the text. The group I, in its majority experienced difficulty in drawing up an endpoint in close relationship with the parties that comprised the text. They did not, however, difficult to define and maintain the main character throughout the story written, even when the story was incoherent if we consider other indicators. Qualitatively, the texts of the students with Down syndrome differed from those produced by the group II.
\end{abstract}

Keywords: textual production; Down syndrome; textual coherence.

\title{
Introdução
}

Os estudos realizados por (ALVES, 1987; BONETI, 1995, 1996, 1997, 1999; GOMES, 2001; MARTINS, 1996; MOURA, 1997) sobre o aprendizado da leitura e da escrita com alunos com síndrome de Down e deficiência intelectual, revelaram semelhanças dos processos cognitivos em relação aos das crianças sem deficiência, embora o ritmo de aprendizagem se diferencie, requerendo, portanto, um período mais longo para a aquisição desse conhecimento. Outros estudos (BENZONI, 1998; JATOBÁ, 1995; MIRANDA, 1999; SOLER, 2001) também verificaram que esses sujeitos atingiam a escrita alfabética, observandose ainda os mesmos níveis identificados por Ferreiro e Teberosky (1986).

Os raros estudos que contam com a participação de alunos com síndrome de Down (ALABARSE, 2002; BALLABEN, 2001; COUSSEAU, 2001; FA- 
RIA, 1993; POTRICH, 1999; RABELO, 2002) se concentram em investigar sobre a evolução da escrita desses alunos, bem como suas possibilidades de se desenvolver e construir conhecimentos. Os dados destes estudos indicaram que esses indivíduos tinham capacidade de aprender a escrever, e esta capacidade é influenciada pela forma como o professor concebe seu objeto de ensino e ainda pelas suas expectativas diante da capacidade de aprendizagem desses sujeitos.

Verifica-se que as pesquisas relativas ao processo de aprendizagem da língua escrita em alunos com deficiência intelectual ainda são raras, e não se concentram em explicitar como esses sujeitos constroem o texto escrito. Percebe-se, nos estudos realizados, que se privilegia os esclarecimentos das habilidades requeridas para o aprendizado da leitura e da escrita, sendo esta preocupação realizada de modo isolado (FIGUEIREDO, 2001).

Este artigo apresenta um estudo comparativo sobre a produção textual, cujas bases de investigação foram constituídas nas sessões individuais de avaliação realizadas com alunos do $2^{\circ}$ ao $8^{\circ}$ anos. Revela, pois, uma investigação sobre o desenvolvimento da linguagem escrita em sujeitos com e sem síndrome de Down, verificando particularmente a coerência textual.

Este artigo apresenta uma base de análise dos textos produzidos a partir dos aspectos relativos à coerência narrativa. Esse aspecto foi analisado a partir da reescrita do conto de Rapunzel, tendo como objetivo verificar se as produções textuais sob o ponto de vista da coerência textual tinham continuidade e progressão.

O desenvolvimento da pesquisa de campo consistiu em sessões individuais de avaliação, e contou com a participação de 9 alunos com e sem síndrome de Down, cuja escolaridade variava entre o $2^{\circ}$ e o $8^{\circ}$ ano do Ensino Fundamental. Deste modo, para investigar a produção textual dos sujeitos do presente estudo, utilizamos os seguintes procedimentos: reconto escrito de uma história; leitura feita por nós do conto de Rapunzel, seguida da solicitação para que cada sujeito reescrevesse o conto.

O presente artigo focalizou as interpretações escritas efetuadas pelos sujeitos sobre a leitura do conto de Rapunzel realizada pela pesquisadora, destacando particularmente a coerência narrativa.

\section{Fundamentação teórica}

Para o referencial teórico deste trabalho, é fundamental a concepção de texto, bem como as referências sobre coerência textual. A definição sobre texto se 
apoia na concepção de textualidade, que se trata de um conjunto de propriedades que permitem a organização de uma sequência linguística e não um amontoado de frases e expressões sem relação entre si.

No presente trabalho optamos pela definição de Teberosky e Tolchinsky (2003, p. 89), que consideram texto "como o conjunto de enunciados linguísticos autossuficientes, organizados seletivamente em função do gênero a que pertencem". O texto, "geralmente, ainda que não necessariamente, está constituído por vários enunciados que tratam do mesmo tema" (TEBEROSKY; TOLCHINSKY, 2003, p. 89).

A composição de textos pressupõe conhecer as normas de como organizar esta linguagem na sua forma gráfica. Teberosky e Tolchinsky (2003) denominam esse conhecimento de notacional. Para que um aluno seja capaz de reconhecer o que é um texto, devemos considerar seu conhecimento letrado e as experiências com leitura e escrita.

Segundo Rocha (1993), ao produzir um texto, o indivíduo realiza uma proposta de compreensão ao seu interlocutor, "e, nesse processo, desenvolve ações com a linguagem e sobre a linguagem" (p. 41).

Ainda em relação à estrutura do texto, consideramos que a coerência procura dar origem à textualidade. Ela hierarquiza os elementos de um determinado texto. Segundo Koch e Travaglia (1995, p. 26), "textualidade ou textura é o que faz de uma sequência linguística um texto e não uma sequência ou um amontoado aleatório de frases ou palavras". Os autores afirmam ainda que

A coerência é vista como uma continuidade de sentidos perceptível no texto, resultando numa conexão conceitual cognitiva entre elementos do texto. Essa conexão não é apenas do tipo lógico e depende de fatores socioculturais diversos, devendo ser vista não só como o resultado de processos cognitivos, operantes entre os usuários, mas também de fatores interpessoais como as formas de influência do falante na situação de fala, as intenções comunicativas dos interlocutores, enfim, tudo que se possa ligar a uma dimensão pragmática da coerência $(\mathrm{KOCH}$; TRAVAGLIA, 1995, p. 12).

A coerência está relacionada ao sentido do texto, sendo um princípio de interpretação que confere ao texto uma unidade e relação entre seus elementos. Marcuschi (1983) define a coerência como uma conexão conceitual-cognitiva manifesta macrotextualmente, referindo-se à sua potencialidade em transmitir conhecimentos de forma a expressar a existência de um sentido, que garante a 
compreensão de um texto. Assim, a coerência é um produto de combinação de conceitos e relações dentro de uma rede composta por tópicos.

No presente trabalho, adotamos a definição de texto apoiados na concepção de textualidade. Desse modo, o texto se organiza em uma sequência linguística, cuja composição é de palavras e frases que se inter-relacionam de modo interdependente. A tessitura textual está relacionada a vários fatores, dentre eles destaca-se a coerência, sendo este o aspecto que trata o presente artigo.

\section{A produção textual de alunos com e sem síndrome de Down: uma análise da coerência narrativa}

A análise das produções textuais será realizada sob a perspectiva da coerência na sequência narrativa. Koch e Travaglia (1995) revelam sua preocupação quanto à dificuldade em definir coerência. Segundo os autores, na literatura, nenhum dos conceitos é capaz de conter todos os aspectos que definem coerência. Assim, eles apresentam algumas definições com o objetivo de refletir sobre cada uma delas.

A primeira diz respeito à compreensão de que coerência significa o cuidado em elaborar um texto que possa permitir boa interlocução com o leitor. "Portanto, a coerência é algo que se estabelece na interação, na interlocução, numa situação comunicativa entre dois usuários" (KOCH; TRAVAGLIA, 1995, p. 11). Outra definição apresentada pelos autores refere-se à compreensão da coerência como uma continuidade de sentidos que deve ser percebida na produção textual, "resultando numa conexão conceitual cognitiva entre elementos do texto" (KOCH; TRAVAGLIA, 1995, p. 12). Os autores acrescentam ainda que "essa conexão não é apenas do tipo lógico e depende de fatores socioculturais diversos" (KOCH; TRAVAGLIA, 1995, p. 12). Isto significa que ela não é resultante apenas de processos cognitivos, mas também de "fatores interpessoais, como a intenção comunicativa entre os interlocutores" (KOCH; TRAVAGLIA, 1995, p. 12). Ao concluir suas reflexões sobre essas definições, eles acrescentam que a coerência é global e obedece a uma hierarquia dos elementos do texto, sendo, portanto, subjacente à sua superfície. Essas definições implicam afirmar que a coerência é um princípio de interpretabilidade que possibilita a compreensão textual. "O estudo da coerência poderia ser visto como uma teoria do sentido do texto" (KOCH; TRAVAGLIA, 1995, p. 13).

O estudo realizado por Costa Val (1996) também é de grande importância para a compreensão do significado de coerência textual. Sua pesquisa objetivou 
analisar as redações de vestibulares. Para isso, ela considerou quatro requisitos: continuidade, progressão, não-contradição e articulação. De acordo com a pesquisadora, esses requisitos foram constituídos a partir da definição de Charolles (1978, apud COSTA VAL, 1996) a respeito de coerência. Segundo Costa Val (1996), a continuidade se manifesta pela retomada de conceitos, de ideias. Já "a progressão é percebida pela soma de ideias novas às que já vinham sendo tratadas" (COSTA VAL, 1996, p. 23). Segundo a autora, o terceiro requisito, o da não-contradição, "deve ser observado tanto no âmbito interno quanto no âmbito das relações do texto com o mundo a que se refere" (COSTA VAL, 1996, p. 24-25). O quarto e último requisito é o da articulação. Ao avaliar a articulação das ideias, devemos verificar se elas têm relação umas com as outras e qual é o tipo de relação estabelecida entre elas.

Já Van Dijk (1981) e Van Dijk e Kintsch (1983) (in: KOCH; TRAVAGLIA, 1995, p. 19) assinalam que "o termo coerência pode ser usado em sentido geral para denotar que alguma forma de relação ou unidade no discurso pode ser estabelecida". Esses autores consideram a coerência uma propriedade lógica do texto, que "se estabelece numa situação comunicativa entre usuários que têm modelos cognitivos comuns ou semelhantes, adquiridos em dada cultura" (KOCH; TRAVAGLIA, 1995, p. 19).

Tendo como referência essas definições, analisamos a coerência na sequência narrativa de nove textos produzidos pelos sujeitos participantes organizados em dois grupos. O grupo I, formado por seis alunos com síndrome de Down, e o grupo II, por três estudantes sem qualquer tipo de deficiência. Essa análise foi realizada com base na compreensão de que coerência implica considerar a existência de uma relação de sentido entre os elementos que compõem os textos, bem como suas sequências consecutivas e inter-relacionadas.

Dentre os nove textos narrativos produzidos pelos dois grupos, cinco indicaram a preocupação com a coerência na sequência narrativa. Desse total, todos os três textos apresentados pelo grupo II tiveram esse cuidado. Em relação ao grupo I, das seis produções, em duas, foi possível identificar a coerência na sequência narrativa. Tomando como base as produções do grupo I, os sujeitos apresentaram a menor quantidade de produções com a devida coerência na sequência narrativa. Assim, dois dentre os seis sujeitos escreveram respeitando a coerência.

A análise da presença da coerência textual será ilustrada por meio de alguns textos produzidos pelos grupos. Assim, os textos produzidos por Levi ( $5^{\circ}$ ano) e Maria Luisa ( $8^{\circ}$ ano), pertencentes ao grupo I, e os de Pedro ( $3^{\circ}$ ano), Sílvia ( $4^{\circ}$ ano) e Ruth $\left(4^{\circ}\right.$ ano), do grupo II, serão referência para análise da presença da coerência textual. 
Na reescrita do conto de Rapunzel, Levi (texto 1) acrescentou palavras que não pertenciam ao contexto do texto lido, no entanto, tal ação não comprometeu o desenvolvimento e a progressão de suas ideias. Assim, ele demonstrou capacidade de articular fatos que se assemelhavam, atentando para sua experiência cotidiana. Essa ligação com seu cotidiano pode ser encontrada no início de seu texto: "[...] e queria vingança igual Soraia Montenegro na novela Maria do bairro". Em sua fala, o aluno revelou que essa personagem seria má, igual à feiticeira da história de Rapunzel. A dificuldade em definir e manter um tópico

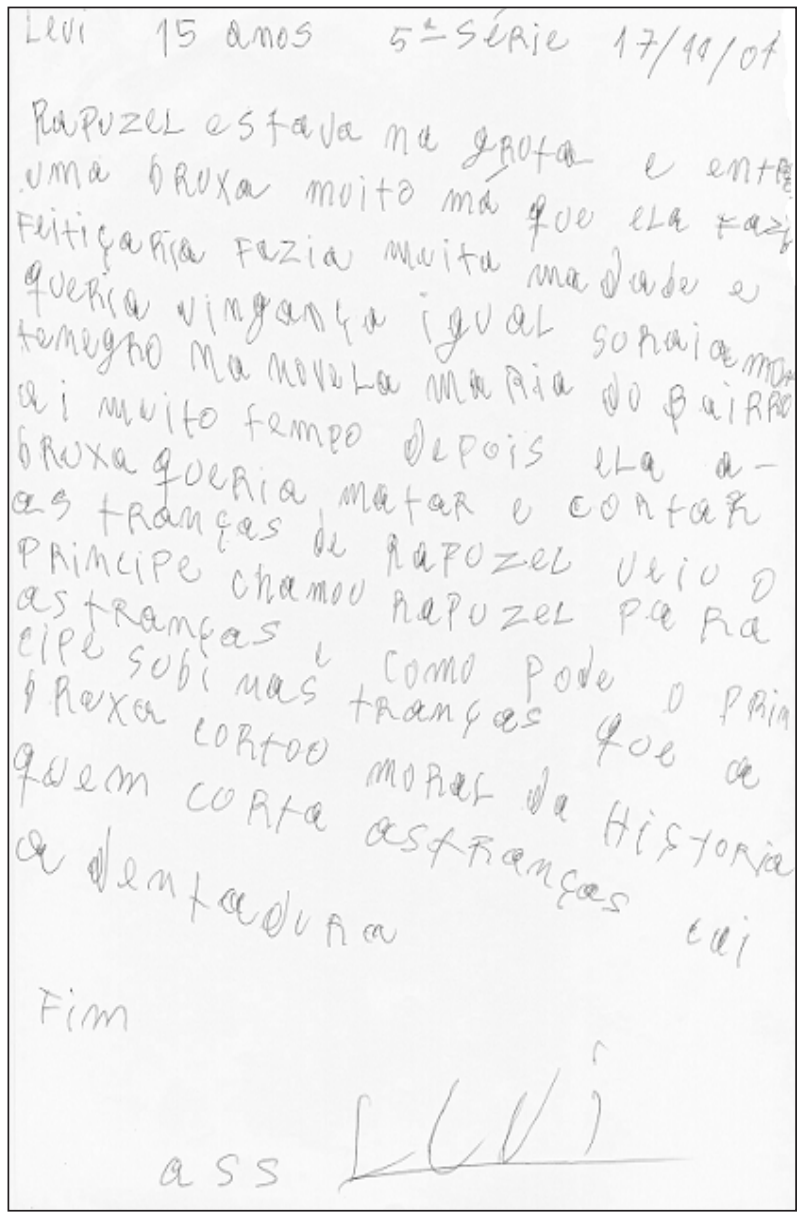

Texto 1 - Reescrita do conto Rapunzel. 
ao longo do texto pode comprometer a relação entre o principal evento e seu desfecho final, incluindo os demais eventos narrados. No caso do texto de Levi, entretanto, verificamos sua capacidade de recuperar a progressão de suas ideias, relacionando-as com os eventos da narrativa. $\mathrm{O}$ trecho a seguir dá continuidade à frase já exemplificada e ilustra essa recuperação: “[...] ai muito tempo depois ela a bruxa queria matar e cortar as tranças de rapuzel veio o príncipe chamou rapuzel para as tranças e como pode o príncipe subir nas tranças que a bruxa cortou [...]".

Já na produção de Pedro ( $3^{\circ}$ ano), do grupo II, ele apresentou indícios de experiência com o texto narrativo. Sua escrita revelou uma organização que demonstrou seu conhecimento acerca dessa estrutura. Foi possível verificar a presença da continuidade de seu texto, mediante a retomada de suas ideias. Pedro, em seu texto, se comprometeu com o tópico e manteve coerência ao longo de sua narrativa. Apresentou, portanto, episódios conectados com um desfecho final. A seguir a ilustração de um trecho retirado da produção de Pedro.

\section{[...] Se eu não pegasse minha molhe vai morrer, ela diss}

pode paga mas quando sua filha nasser você mida ele aceitou quando a filha nasseu ela foi e pegou e deu o nome de rapunzeu (...)

Outras características também estão presentes no texto de Pedro, porquanto revelam seu cuidado quanto à progressão, à não-contradição e à articulação de suas ideias. $\mathrm{O}$ trecho inicial de sua produção indica tal cuidado.

Era uma vez um casau que quiria muito ter filho. Ela vio raponsso na casa da feiticera, ela começou a emagrecer e disse se eu não comer raposso eu vou morrer.

Então o marido dela foi lá [...]

Em relação à ausência de coerência textual, foram destacadas as produções de Samara ( $2^{\circ}$ ano), de Lya ( $3^{\circ}$ ano), de Beatriz ( $4^{\circ}$ ano) e de Ana Paula ( $6^{\circ}$ ano), todas do grupo I. Para exemplificar essa ocorrência, destacamos apenas a reescrita do conto de Rapunzel, realizada por Samara ( $2^{\circ}$ ano).

No texto de Samara, identificamos algumas informações sobre o conto lido. Em sua produção, ela buscou estratégias baseadas em conhecimentos que possuía sobre o seu conteúdo, ou ainda se baseou em fatos relevantes que conseguiu ativar em sua memória. $\mathrm{O}$ texto que envolve sua reescrita implica uma atividade complexa, que, além da capacidade de mobilizar conhecimentos, exige uma habilidade de planejar a escrita para que possa guiar e articular as ideias, e, assim, conseguir uma articulação entre as frases. Essa dificuldade 
interfere na possibilidade de estabelecer relações entre as ideias contidas no texto. Na tentativa de produzir um texto coerente, a aluna não foi capaz de explicitar os eventos iniciais, nem os demais complicadores e seu desfecho. O desenvolvimento da habilidade de narrar envolve, dentre outros aspectos, a capacidade de estabelecer relação de coerência e coesão, além da apropriação do esquema narrativo.

No texto de Samara, exemplificado a seguir, foi possível distinguir algumas frases que apresentavam relação com o conteúdo lido por nós, apesar de ela não ter apresentado continuidade na expressão escrita dos eventos pertencentes ao conto.

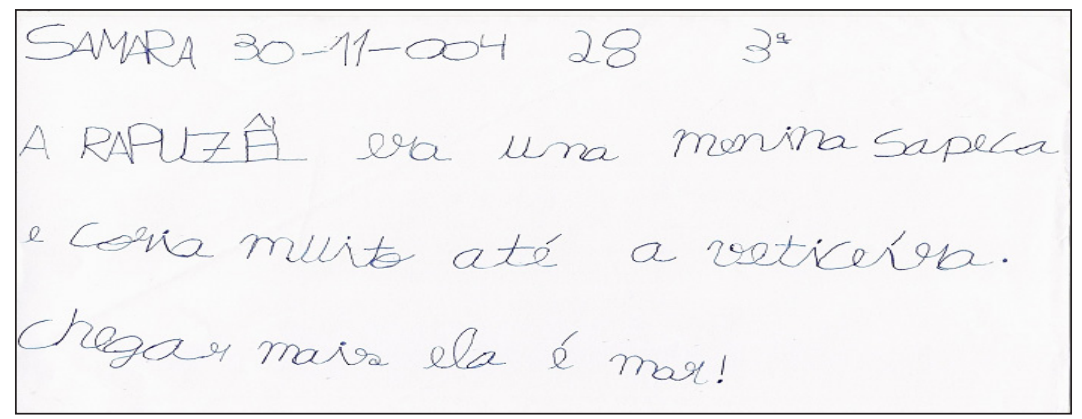

Texto 2 - Reescrita do conto Rapunzel.

Sanches (2002), ao se referir às fragilidades nas produções textuais, salienta que a não-percepção das relações entre as ideias do texto dificulta

[...] a organização temática que ajuda a identificar as ideias globais, ou dos conectores que indicam as relações entre as ideias. Assim, está provado que os sujeitos de menor compreensão mostram menos capacidade para reconhecer o padrão organizativo dos textos. (SANCHES, 2002, p. 130).

$\mathrm{O}$ autor acrescenta ainda que essas dificuldades ocorrem em razão de um menor contato com os textos ou de um convívio com êxito menor do que o normal. Outra justificativa diz respeito à mobilização de estratégias, que permitem operar com a informação do texto. Em relação a esse aspecto, Sanches (2002, p. 131) evidencia que os alunos "encontram dificuldades para transformar as palavras do texto em suas próprias palavras, para identificar o tema específico tratado em cada parágrafo, ou para impor, por si mesmos, ordem às ideias". 
Outra dificuldade ainda referida pelo mesmo autor diz respeito à capacidade de autorregular a compreensão, isto é, de planejar seu contato com o texto e detectar incoerências. A capacidade de detectar essas incoerências nem sempre esteve presente em alguns dos textos do grupo I.

A preocupação quanto à coerência na sequência narrativa evidencia a necessidade de integração do diálogo interior com o potencial leitor. Essa integração indica uma preocupação quanto à continuidade, progressão e articulação das ideias para que o texto se torne inteligível. Essas afirmações permitem concluir que a coerência se importa com os sentidos de um texto, expressando a sua lógica interna, com a finalidade de promover a inter-relação dos elementos do discurso escrito.

Como visto, alguns textos produzidos pelos sujeitos do grupo I não tinham coerência. Este fato evidenciou fragilidades quanto ao domínio em selecionar, controlar e organizar as ideias para elaborar um texto coerente.

Os dados revelaram que os alunos do grupo II, embora produzindo textos mais longos, operavam com maior competência com os elementos que traduziam o cuidado quanto à coerência na sequência narrativa. Nos dois grupos, a coerência na sequência narrativa apareceu, embora fosse mais frequente nas produções apresentadas pelo grupo II. Esse grupo apresentou estratégias poderosas para mobilizar os recursos cognitivos que permitiram articular os conhecimentos anteriores e focalizá-los na produção e na articulação de suas ideias no texto.

\section{Algumas considerações}

Concluímos que a maioria dos alunos do grupo I revelou dificuldades na tentativa de produzir um texto coerente. Verificamos, por exemplo, que alguns desses sujeitos experimentavam dificuldades em elaborar um desfecho em estreita relação com o evento principal e com os eventos narrados. Não apresentaram, porém, dificuldades em definir e manter a personagem principal ao longo de toda a história escrita, mesmo quando a história era incoerente se considerarmos outros indicadores. O estudo realizado por Spinillo (1997) evidenciou semelhante resultado. Em sua pesquisa, a autora examinou as possibilidades e dificuldades de crianças de 6-7 anos em estabelecer a coerência ao produzir um texto. Seus resultados indicaram que, de forma precoce, a criança domina a indicação e a manutenção da personagem central em seus textos.

As produções escritas dos alunos, tanto do grupo I quanto do grupo II, apresentaram marcas heterogêneas. Essas se traduziam, principalmente, no as- 
pecto relacionado ao desempenho no interior de cada grupo, quanto à coerência narrativa. Esses resultados indicaram a inexistência de uma característica comum nas produções textuais de cada um dos grupos. Nessa perspectiva, a heterogeneidade se manifestou em ambos os grupos. Qualitativamente, os textos dos alunos com síndrome de Down se diferenciaram daqueles produzidos pelo grupo II. Não identificamos, porém, características que podem representar especificidades na produção escrita dos alunos com essa síndrome, visto que alguns alunos com síndrome de Down produziram textos apresentando coerência narrativa, mesmo considerando que tal ocorrência se apresentou em menor quantidade se compararmos com as produções dos alunos do grupo II.

A análise dos textos revelou, ainda, que a escrita de um texto envolve uma operação gradual de controle consciente de um conjunto de ações, que implicam operações cognitivas e metacognitivas. Essas operações promovem o desenvolvimento da capacidade metalinguística. Essa habilidade pressupõe capacidade de controlar e monitorar o pensamento, sendo estas operações da ordem da metacognição. Estudos recentes (MARTIN; MARCHESI IN COLL, 1995; FIGUEIREDO, 2001, 2002; FIGUEREIDO \& GOMES, 2003a, 2003b) indicam que os sujeitos com deficiência intelectual apresentam fragilidade metacognitiva, fato que interfere na capacidade do sujeito em regular e controlar o próprio conhecimento. Essa dificuldade compromete os processos de monitoramento e de planejamento das ações. Todas essas fragilidades parecem interferir na qualidade da produção textual desses sujeitos.

Olson (1997, p. 273-274) assinala que, para compreender as implicações conceituais e cognitivas da escrita, é necessário

[...] distinguir os recursos cognitivos envolvidos na percepção, na fala e na ação (processos cuja origem precisa ser explicada em termos evolutivos), dos processos cognitivos implicados na criação, armazenamento e uso de artefatos e símbolos que têm funções de representação (processos e produtos cujas origens precisam ser explicadas cultural e historicamente).

A escrita possibilita que os indivíduos dominem melhor os processos psíquicos de planejamento, controle e gestão da linguagem: "[...] trata-se de conceber a linguagem escrita como a álgebra da linguagem, cuja apropriação permite à criança ascender ao plano abstrato e mais elevado da linguagem, ao mesmo tempo em que reorganiza o sistema psíquico anterior da linguagem oral" (VYGOTSKY apud CARDOSO, 2003, p. 89-90). 
Ainda em relação às produções realizadas por quatro sujeitos do grupo I, vários textos expressaram dificuldades na recomposição do sentido global dos eventos narrativos. Esses sujeitos desse grupo demonstraram compreensão episódica ou desconexa dos eventos narrativos presentes nos textos, comprometendo a coerência textual. Essa falta de compreensão pode estar relacionada à dificuldade de apreender os eventos presentes na narrativa para, em seguida, reescrevê-los. Nesse tipo de texto, a exigência na capacidade de fixar alguns caracteres, como as personagens, ações e enredos, demanda o uso de habilidades metacognitivas de detecção do sentido global do texto, a partir desses indícios principais. Nesse sentido, a reescrita de um texto ultrapassa a mera repetição de situações presentes, enfatizando a monitoração do pensamento para construção de sentido. Nesse caso, a reescrita se configura como uma habilidade que envolve um conjunto de estratégias cognitivas e metacognitivas, exigindo daquele que escreve uma capacidade de organizar, planejar, monitorar e controlar suas ações com vistas a produzir sentido em seu texto.

No presente estudo, os dados revelaram, ainda, indícios de um enorme esforço dos sujeitos para atenderem a nossa solicitação, durante os encontros de avaliação da produção textual. Este esforço pôde ser observado nas relações que eles buscavam estabelecer entre o momento de escuta da leitura do texto e a sua produção escrita. As atividades que exigem a utilização da memória de trabalho podem interferir no desempenho de sujeitos com síndrome de Down. Na pesquisa desenvolvida por Figueiredo (2005), os sujeitos com deficiência intelectual revelaram dificuldades para reescrever textos narrativos, indicando, ainda, que alunos com deficiência intelectual apresentam dificuldades de compreensão, memória e organização dos aspectos objetivos que compõem a notação escrita.

Alguns sujeitos do grupo I, ao longo da reescrita, demonstravam dificuldades expressadas principalmente no esforço demonstrado para compreender o detalhamento das situações presentes no texto. A principal delas se referia à dificuldade em reconstruir a trama do texto narrativo e, consequentemente, estabelecer relação de coerência entre as partes componentes. Parece que essa dificuldade se acentuava porque a reescrita de um texto exige um nível mais avançado de funcionamento cognitivo, por apresentar grau elevado de complexidade. Apesar dessas dificuldades, todos os sujeitos do grupo I foram capazes de formalizar sua escrita, aspecto que demonstrou sua capacidade de utilizar maior grau de abstração, uma vez que a linguagem escrita é uma aprendizagem simbólica e conceitual.

Com o intuito de evidenciar as produções do grupo II, destacamos as dificuldades mais comumente encontradas. Essas diziam respeito, principalmente, à seleção, organização e sequência dos eventos narrativos com vistas ao esta- 
belecimento da coerência. A maioria dos sujeitos desse grupo parecia centrar-se mais na coerência da sequência dos eventos, aliando o seu conhecimento de mundo sobre o tema apresentado. Suas produções apontaram para uma atitude de reflexão sobre o texto escrito e a própria linguagem que deviam utilizar, já que parecia que alguns tinham consciência de que o texto escrito contém uma linguagem que difere da oral.

Os textos do grupo II trouxeram marcas visíveis de operações de reelaboração. Ao longo da produção dos textos, havia indícios dessas operações. Estas podem ser representadas pelos borrões e inserções de palavras, após sua leitura. Nesse sentido, os sujeitos deste grupo, em comparação com os do grupo I, demonstraram maior preocupação quanto à revisão da escrita. Durante as produções, houve indícios de monitoramento e controle da escrita, fatos que ocorreram por meio das pausas frequentes durante a reescrita dos textos.

A evolução da capacidade de escrita implica um crescente contato com essa linguagem, que envolve também a possibilidade de propiciar seu desenvolvimento por meio de experiências que compreendem as diferentes dimensões envolvidas para tal aquisição. Essas dimensões dizem respeito às oportunidades socioculturais e escolares.

\section{REFERÊNCIAS}

ALABARSE, Valéria Mondin. Estudo do desenvolvimento cognitivo e da linguagem em crianças com síndrome de Down. 2002. Dissertação (Mestrado em Ciências - Fisiopatologia Experimental) - Universidade de São Paulo, São Paulo, 2002.

ALVES, José Moysés. Estudo sobre a relação entre a extensão falada/escrita de palavras, por crianças portadoras de sindrome de Down. 1987. Dissertação (Mestrado em Educação) - Universidade Federal de São Carlos, São Carlos, 1987.

BALLABEN, Maria Cecília Guimarães. Interações em sala de aula: fatores que favorecem a aprendizagem de alunos com síndrome de Down. 2001. Dissertação (Mestrado em Educação) - Universidade Estadual de Campinas, Campinas, 2001.

BENZONI, Selma Aparecida Geraldo. Avaliação de crianças com queixa de dificuldade na aprendizagem escolar, diferenciadas quanto ao nivel cognitivo. 1998. Dissertação (Mestrado em Educação) - Universidade de São Paulo, São Paulo, 1998.

BONETI, Rita Vieira de Figueiredo. L'émergence du language écrit chez les enfants présentant une déficience intellectuelle. Québec: Université Laval, 1995. 
. Le dévelopment du language écrit chez les enfants présentant une déficience intelectuelle: L'interprétation du prenomé. Archieves Psychologie, Genebre, n. 64, 1996.

. A interpretação da escrita pela criança portadora de deficiência intelectual. In: REUNIÃO ANUAL DA APENd, 20., 1997, Caxambu. [Trabalho apresentado]. Caxambu, 1997.

. A interpretação da escrita pela criança portadora de deficiência intelectual. Revista Brasileira de Educação Especial, v. 3, n. 5, set. 1999.

COSTA VAL, M. A. M. Entre a oralidade e a escrita: desenvolvimento da representação do discurso narrativo escrito em crianças em fase de alfabetização. 1996. Tese (Doutorado em Educação) - Universidade Federal de Minas Gerais, Belo Horizonte, 1996.

CARDOSO, Cancionila Janzkovski. A socioconstrução do texto escrito: uma perspectiva longitudinal. Campinas, SP: Mercado de Letras, 2003.

COUSSEAU, Salete Rocio. A aquisição da escrita por portadores da sindrome de Down. 2001. Dissertação (Mestrado em Psicologia) - Universidade Federal do Paraná, Curitiba, 2001.

FARIA, Maria Natalia Mesquita de. Alfabetização de crianças portadoras de síndrome de Down: analisando uma proposta de ensino. 1993. Dissertação (Mestrado em Educação Especial) - Universidade Federal de São Carlos, São Carlos, 1993.

FERREIRO, Emília; TEBEROSKY, Ana. Psicogênese da língua escrita. Porto Alegre: Artmed, 1986.

FIGUEIREDO, R. V. Leitura, cognição e deficiência mental. In: ENCONTRO DE PESQUISA EDUCACIONAL DO NORTE E NORDESTE, 15., 2001, São Luís. Educação, Desenvolvimento Humano e Cidadania. [Trabalho apresentado]. São Luís, 2001.

. A emergência de estratégias de leitura em crianças e jovens com deficiência mental. Relatório de pesquisa - CNPq. Fortaleza, 2002.

. L'apprentissage des systèmes de notation pour des élèves présentant une déficience intellectuelle. In: COLÓQUIO INTERNACIONAL. Noter Pour Penser. Anais... França: Universidade de Angers, 2005.

; GOMES, Adriana. L. Limaverde. L'apprentissage de la lecture d'élèves porteurs de retard intellectuel issus de classe moyenne ou défavorisée. In: Colloque international de l'AFEC. Dijon 2003a.

; _. A emergência das estratégias de leitura em sujeitos com deficiência mental. In: REUNIÃO DA ANPEd, 26., 2003. [Trabalho apresentado]. Poços de Caldas - MG, 2003b.

GOMES, Adriana L. Limaverde. Leitores com síndrome de Down: a voz que vem do coração. 2001. Dissertação (Mestrado em Educação) - Universidade Federal do Ceará, Fortaleza, 2001. 
JATOBÁ, Carla Mercês da Rocha. Eles conseguem: estudo sobre alfabetização em crianças com síndrome de Down. 1995. Dissertação (Mestrado em Educação) - Universidade Federal do Rio Grande do Norte, Natal, 1995.

KOCH, Ingedore Grunfeld Villaça; TRAVAGLIA, Luiz Carlos. Texto e coerência. São Paulo: Cortez, 1995.

MARCUSCHI, L. A. Linguística de texto: como é e como se faz. Série Debates 1. Universidade Federal de Pernambuco, Mestrado em Letras e Linguística, 1983.

MARTIN, Ellen; MARCHESI, Álvaro. Desenvolvimento metacognitivo e problemas de aprendizagem. In: COLL, César. Desenvolvimento psicológico e educação. Porto Alegre: Artes Médicas, 1995.

MARTINS, Nadia Cesar da Silveira. Crianças com sindrome de Down: relações entre fala, gestos e produção gráfica. 1996. Dissertação (Mestrado em Educação) - Universidade Federal de São Carlos, São Carlos, 1996.

MIRANDA, Claudia Celencina Carvalho de. O que dizem as letras? - O início do processo de aquisição da linguagem escrita em portadores de síndrome de Down - Duque de Caxias, RJ. 1999. Dissertação (Mestrado em Educação) - Universidade do Estado do Rio de Janeiro, Rio de Janeiro, 1999.

MOURA, Vera. O poder do saber: relato e construção de uma experiência em alfabetização. Porto Alegre: Kuarup, 1997.

OLSON, David. O mundo no papel. São Paulo: Ática, 1997.

POTRICH, Jurema Kalua. O desenvolvimento da criança com síndrome de Down: as questões que remetem a um diferencial significante. 1999. Dissertação (Mestrado em Ciências do Movimento Humano) - Universidade Federal do Rio Grande do Sul, 1999.

RABELO, Gabriela Monteiro. Alfabetização e sindrome de Down: um estudo microanalítico. 2002. Dissertação (Mestrado em Psicologia) - Universidade de Brasília, Brasília, 2002.

ROCHA, Iúta Lerche Vieira. Ensinando a redigir: do processo ao produto. Apostila do curso de atualização em língua portuguesa - Fundamentos para a prática da leitura e produção de textos. Universidade Federal do Ceará, 1993.

SÁNCHEZ, Emílio Miguel. Compreensão e redação de textos: dificuldades e ajudas. São Paulo: Artmed, 2002.

SOLER, Laís Aparecida Fernandes. Alfabetização e suas relações com a construção do conhecimento: um estudo em deficiência mental leve. 2001. Dissertação (Mestrado em Educação) - Universidade de São Paulo, São Paulo, 2001.

SPINILLO, Alina Galvão. Uma análise da produção de histórias coerentes por crianças. Psicologia, Reflexões e Críticas, Porto Alegre, v. 1, n. 2, 1997. 
GOMES, A. L. L. A produção escrita de alunos com e sem síndrome de Down: uma análise...

TEBEROSKY, Ana; TOLCHINSKY, Liliana. Além da alfabetização: a aprendizagem fonológica, ortográfica, textual e matemática. São Paulo: Ática, 2003.

Texto recebido em 25 de setembro de 2012.

Texto aprovado em 22 de março de 2013. 